\title{
Henoch-Schönlein purpura in pediatrics: Ten years of experience at a moderate risk office of a general hospital
}

\author{
Silvia Gómez, M.D. ${ }^{a}$, Mariela Pérez, M.D. ${ }^{b}$, Mariana Pellegrini, M.D. ${ }^{c}$, \\ Elsa Isern, M.D. ${ }^{c}$, Cecilia Quintana, M.D. ${ }^{d}$, Patricia Artacho, M.D. ${ }^{a}$, \\ Margarita Bertolini, M.D. ${ }^{a}$, Bettina Pomerantz, M.D. ${ }^{a}$ and Natalia Gadda, M.D. ${ }^{a}$
}

\begin{abstract}
Introduction. Henoch-Schönlein purpura (HSP) is the most common small vessel leukocytoclastic vasculitis during childhood. It is characterized by palpable purpura and / or joint, abdominal or renal involvement.

Objective. To describe the epidemiological, clinical, laboratory, and evolutionary characteristics of patients with HSP.

Population and methods. Observational, descriptive, and retrospective study. Patients younger than 15 years who met the Ankara criteria for HSP diagnosis were included in the period between $1 / 1 / 2008$ and $12 / 31 / 2017$.

Results. A total of 339 patients with HSP were included; the male/female distribution was similar; their average age at onset was 7.02 years $( \pm 3.02)$. The typical form was observed in $78 \%$ and the atypical form, in $22 \%$, with joint involvement prior to purpura onset. Joint manifestations: $82 \%$; abdominal involvement: $54 \%$; renal manifestations: $19 \%$. Among patients with renal involvement, $68 \%$ experienced it in the first month after onset. The most common symptom was isolated hematuria, and $22 \%$ of patients with renal involvement had moderate to severe nephritis. Recurrences were observed in $15 \%$ of patients.

Conclusion. Joint manifestations were more common than what has been described in other series, whereas renal involvement was less common. Although it usually occurs in the first months of disease onset, it is worth noting that these patients need follow-up with urinary and blood pressure controls as part of their pediatric assessment.

Key words: Henoch-Schönlein purpura, children, retrospective studies.
\end{abstract}

http: / / dx.doi.org/10.5546/aap.2020.eng.31

To cite: Gómez S, Pérez M, Pellegrini M, Isern E, et al. Henoch-Schönlein purpura in pediatrics: Ten years of experience at a moderate risk office of a general hospital. Arch Argent Pediatr 2020;118(1):31-37.

\section{E-mail address:}

Silvia Gómez, M.D.:

slgomez@intramed.net

Funding:

None

Conflict of interest:

None.

Received: 1-30-2019

Accepted: 8-11-2019

\section{INTRODUCTION}

Henoch-Schönlein purpura (HSP) is the most common small vessel leukocytoclastic vasculitis during childhood. ${ }^{1-5}$ Its incidence varies depending on geographic areas. It ranges from 10 to $20 / 100000$ individuals younger than 17 years per year. The average age at onset is 6 years old. According to most publications, HSP is predominant among males (2:1 ratio) and occurs most commonly during the fall and winter. ${ }^{1-3,4,6}$

It is characterized by palpable purpura (this condition must always be present) and joint, abdominal or renal involvement. ${ }^{1,4}$ It may rarely affect other organs, including the brain, lungs, heart, eyes, testicles, among others, because it is a systemic disease. ${ }^{7-10} \mathrm{HSP}$ is a selflimited and benign condition; it resolves spontaneously over 2 weeks in one third of cases, over 2-4 weeks in another third; and over more than 4 weeks in the rest. ${ }^{2,9,11-14}$ Long-term prognosis is related to renal involvement.

\section{OBJECTIVE}

To describe the epidemiological, clinical, laboratory, and evolutionary characteristics of patients with HSP. To analyze the risk factors associated with renal involvement and recurrence.

\section{POPULATION AND METHOD}

Design: observational, descriptive, and retrospective study.

Site: Moderate Risk Office, Outpatient Pediatric Clinic. Period: $1 / 1 / 2008$ to $12 / 31 / 2017$.

\section{Inclusion criteria}

Patients aged 1-15 years who met 
the 2008 Ankara Consensus Conference criteria seen at the site from disease onset.

\section{Exclusion criteria}

Diagnosis of other prior rheumatic, immune, hematological or renal diseases or current treatment with drugs that may cause purpura. Patients with less than 2 weeks of follow-up since onset.

\section{Data collection}

Medical records were reviewed, and the 2008

Ankara Consensus Conference criteria were considered:

- Purpura (commonly palpable) or petechiae, with lower limb predominance, not related to thrombocytopenia (always present) and at least one of the following:

- Diffuse abdominal colicky pain with acute onset assessed by history or physical examination. It may include intussusception and gastrointestinal bleeding.

- Arthritis of acute onset, defined as joint swelling or joint pain with limitation on motion. Arthralgia: joint pain without joint swelling or limitation on motion.

- Renal involvement: proteinuria $>0.3 \mathrm{~g} / 24 \mathrm{~h}$, $>30 \mathrm{mmol} / \mathrm{mg}$ of urine albumin/creatinine ratio on a spot morning sample. Hematuria: $>5$ red blood cells/high power field in the urinary sediment or $\geq 2+$ on dipstick. Presence of red blood cells casts in the urinary sediment.

- Histopathology: typically leukocytoclastic vasculitis with predominant immunoglobulin A (IgA) deposit or proliferative glomerulonephritis with predominant IgA deposit. $^{2,15}$

\section{Outcome measures}

- Epidemiological characteristics: age, sex, season.

- Clinical characteristics: history (respiratory tract infection, medication, immunizations, in the previous 15 days).

- Typical form: onset with purpura. Atypical form: joint, abdominal or renal involvement prior to purpura onset (in the previous 48 hours).

- Joint involvement: arthralgia, arthritis; abdominal involvement: pain, vomiting, intestinal bleeding; renal involvement: hematuria, proteinuria, nephrotic or nephritic syndrome with or without a fall in filtration rate $(<90 \mathrm{~mL} /$ $\min / 1.73 \mathrm{~m}^{2}$, estimated as per Schwartz' formula). Mild nephritis: asymptomatic macro- or microscopic hematuria and/or non- nephrotic proteinuria ( $>5$ and $<50 \mathrm{mg} / \mathrm{k} /$ day or protein/creatinine ratio [PCR] $<2 \mathrm{mg} / \mathrm{mg}$ ). Moderate to severe nephritis: fall in glomerular filtration rate $<90 \mathrm{~mL} / \mathrm{min} / 1.73 \mathrm{~m}^{2}$ and $/$ or persistent proteinuria in the nephrotic range ( $>50 \mathrm{mg} / \mathrm{k} /$ day or PCR $>2 \mathrm{mg} / \mathrm{mg}$ ) with or without nephritic syndrome and/or arterial hypertension (HTN: blood pressure $>\mathrm{P} 90$ as per the World Health Organization [WHO] tables).

- Baseline lab tests: white blood cell count, hematocrit, hemoglobin, platelet count, C-reactive protein (CRP), IgA level, complement, erythrocyte sedimentation rate.

\section{Evolutionary characteristics:}

- Follow-up duration, hospitalization, administered medication.

- Recurrence: patient with prior diagnosis of HSP, asymptomatic for at least 4 weeks, with new skin lesions and/or systemic manifestations of vasculitis. . $^{16,17}$

- Persistent purpura: patients who were not symptom-free since the initial diagnosis until after 1 year of follow-up or more.

\section{Statistical analysis}

Continuous outcome measures were described as measures of central tendency and dispersion based on sample distribution. Categorical outcome measures were stated as absolute frequency and percentage. The $\chi^{2}$ test or Fisher's exact test were used to study the relation among qualitative outcome measures, based on the two-way table distribution. A value of $p<0.05$ was considered statistically significant. The SPSS Statistics V19 software program was used for analysis.

\section{Ethical considerations}

The protocol was reviewed and approved by the Research and Teaching Coordination and the Hospital Bioethics Committee.

\section{RESULTS}

The medical records of 339 patients were reviewed. The reasons for exclusion are detailed in Figure 1. (Average: 31 patients/year).

\section{Epidemiological and clinical characteristics:}

The average age at onset was $7.02 \pm 3.02$ years, with a similar male/ female distribution (Figure 2). The demographic characteristics and the history of patients are described in Table 1. The median follow-up duration was 75 days (interquartile range [IQR]: 40-120). HSP occurred 
more frequently in the fall $(\mathrm{n}=107)$, followed, in a descending order, by the winter $(n=86)$, spring $(n=81)$, and summer $(n=65)$.

\section{Clinical manifestations}

Onset: 265 patients (78\%) presented with the typical form and $74(22 \%)$, the atypical presentation (Table 2). Unusual symptoms were observed in 41 cases $(12 \%)$, including headache

FIGURE 1. Selection of patients with Henoch-Schönlein purpura

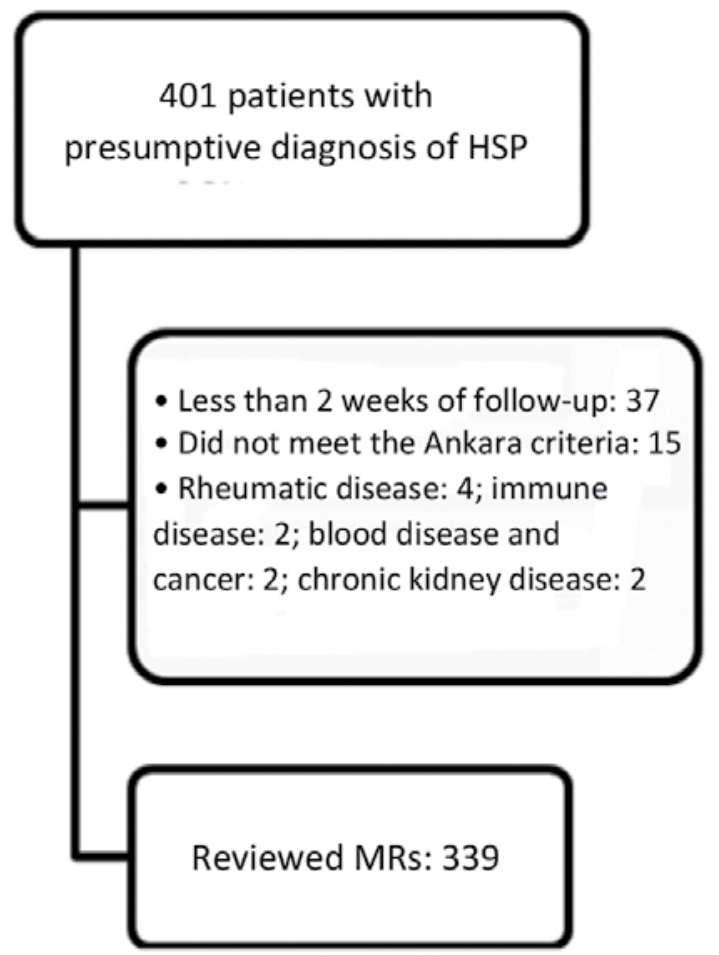

HSP: Henoch-Schönlein purpura; MRs: medical records.
$(14,4 \%)$, bullous purpura $(7,2 \%)$, testicular involvement $(4,10 \%)$, myositis $(1,0.3 \%)$, hemorrhagic conjunctivitis $(1,0.3 \%)$, epistaxis $(1,3.2 \%)$, hemoptysis $(3,1 \%)$.

Joint manifestations were observed in $82 \%$ of patients, with greater lower limb involvement; the most commonly affected joints were the ankles and the knees (Table 3).

Abdominal involvement was confirmed

TABLE 1. Demographic characteristics and history prior to Henoch-Schönlein purpura onset

\begin{tabular}{lc}
\hline & $\mathbf{N}=\mathbf{3 3 9}$ \\
\hline Age at onset (years old) & 7.02 \\
Mean & 3.026 \\
Standard deviation & \\
Sex, $(\%)$ & $172(51)$ \\
Male & $169(49)$ \\
Female & \\
Duration of follow-up (days) & 75 \\
Median & $40-120$ \\
IQR & \\
Season, $\mathbf{n}(\%)$ & $65(19)$ \\
Summer & $107(32)$ \\
Fall & $86(25)$ \\
Winter & $81(24)$ \\
Spring & \\
History, $\mathbf{n}(\%)$ (N: 329) (**) & $204(62)$ \\
URTC & $82(25)$ \\
Beta-hemolytic streptococcus & $17(5)$ \\
Mycoplasma & $2(0.6)$ \\
Medication & $1(0.3)$ \\
Immunizations & $4(1)\left({ }^{*}\right)$ \\
Other & $19(6)$ \\
No history & \\
\hline
\end{tabular}

$\left({ }^{*}\right)$ Food, gastrointestinal infection.

$(* *) 10$ without data.

URTC: upper respiratory tract catarrh;

IQR: interquartile range.

FIGURE 2. Distribution by age and sex of patients diagnosed with Henoch-Schönlein purpura

Distribution by age and sex (N: 339)

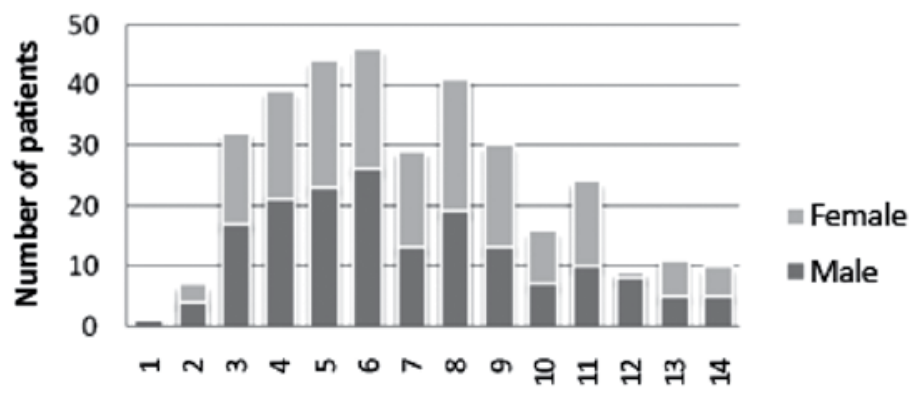

Age (years old) 
in $54 \%$ of cases; pain was the most common symptom. Two patients had intussusception as confirmed by an ultrasound and X-rays. They had severe intestinal bleeding, whereas the remaining patients had little and intermittent bleeding. Scalp edema requiring corticosteroid treatment was observed in $8 \%$ of patients $(n=26)$.

Renal involvement was detected in 65 patients (19\%). Isolated hematuria was the most common manifestation. HTN was detected in 14 patients; in all, it was part of the presentation

TABLE 2. Presentation and symptoms at onset

\begin{tabular}{lc}
\hline & $\mathbf{N}=339$ \\
\hline Clinical presentation: & $\mathbf{n}(\%)$ \\
Typical & $265(78)$ \\
Purpura & $252(95)$ \\
Purpura, abdominal involvement & $7(3)$ \\
Purpura, joint involvement & $5(2)$ \\
Purpura, abdominal and joint involvement & $1(0.4)$ \\
Atypical & $74(22)$ \\
Joint involvement & $51(69)$ \\
Abdominal involvement & $21(28)$ \\
Joint and abdominal involvement & $1(1)$ \\
Renal involvement & $1(1)$ \\
\hline
\end{tabular}

TABLE 3. Clinical manifestations

\begin{tabular}{lcc}
\hline & $\begin{array}{c}\text { Frequency } \\
\mathbf{N}=\mathbf{3 3 9}\end{array}$ & $\begin{array}{c}\text { Percentage } \\
\mathbf{( \% )}\end{array}$ \\
\hline Purpura & 339 & $\mathbf{1 0 0}$ \\
Joint symptoms & $\mathbf{2 7 8}$ & $\mathbf{8 2}$ \\
$\quad$ Arthralgia & 199 & \\
Arthritis & 79 & \\
Involved joints & & \\
$\quad$ Lower limbs & 257 & \\
Upper limbs & 4 & \\
Upper and lower limbs & 18 & \\
Abdominal symptoms & 182 & 54 \\
$\quad$ Abdominal pain & 126 & \\
Gastrointestinal bleeding & 29 & \\
Pain, vomiting & 27 & \\
Renal involvement & 65 & 19 \\
Minimal renal abnormalities & 51 & 78 \\
Isolated hematuria & 27 & \\
Non-nephrotic proteinuria & & \\
Hematuria and non-nephrotic & & \\
proteinuria & 19 & \\
Moderate to severe nephritis & 14 & \\
$\quad$ Nephrotic syndrome & 1 & \\
Nephritic syndrome & 1 & \\
Nephrotic proteinuria & 10 & \\
Fall in filtration rate & 2 & \\
Edema & & \\
Scalp & 26 & \\
Scrotum & 45 & \\
Sacrum & 15 & \\
\hline
\end{tabular}

as nephritic syndrome. Most patients $(44,68 \%)$ had renal involvement in the first month of HSP diagnosis; while $15(23 \%)$, in the first 2 months. The univariate analysis showed that age ( $>10$ years) $(p=0.004)$, abdominal involvement $(p=0.005)$, and recurrence $(p=0.000)$ were statistically significant factors associated with renal involvement.

Patients with moderate to severe nephritis $(n=14)$, defined as per the clinical criteria, were treated based on the modified protocol proposed by Niaud et al.: 3 IV pulses of methylprednisolone ( $\left.1 \mathrm{~g} / 1.73 \mathrm{~m}^{2}\right)$, followed by oral prednisone $\left(30 \mathrm{mg} / \mathrm{m}^{2} /\right.$ day) for a month, then $30 \mathrm{mg} / \mathrm{m}^{2}$ every other day for 2 months, and, finally, 15 $\mathrm{mg} / \mathrm{m}^{2}$ every other day for 15 days (Table 3). Cyclophosphamide was indicated at a dose of $2 \mathrm{mg} / \mathrm{kg} /$ day for 2 months in patients who did not respond to corticosteroids. Total response, defined as normal proteinuria and glomerular filtration rate, was observed in 8 patients; 4 patients had partial response (residual, nonnephrotic proteinuria) with a normal glomerular filtration rate. Two patients did not respond to treatment (persistent nephrotic-range proteinuria and/or no recovery of glomerular filtration rate). Of the 2 patients who did not respond to corticosteroids, 1 showed total response to cyclophosphamide and the other had residual proteinuria. A renal biopsy was done in 8 patients, and the most common histopathological finding was focal mesangial proliferation (III.a according to the International Study of Kidney Disease in Children [ISKDC] classification). ${ }^{18}$ Patients with persistent, non-nephrotic proteinuria received angiotensin II-converting enzyme inhibitors $(n=24)$.

Recurrence: One or more recurrences occurred in 52 patients $(15 \%)$. The median time since the onset of HSP until recurrence was 65 days $(r=30-$ 540). The most common clinical manifestation of recurrence was isolated purpura $(27,52 \%)$, whereas the rest had purpura accompanied with other type of involvement. The outcome measures associated with recurrence in this series were

TABLE 4. Reasons for hospitalization

\begin{tabular}{lcc}
\hline & \multicolumn{2}{c}{ Frequency } \\
& $\mathbf{N}=\mathbf{6 3}$ & $\mathbf{( \% )}$ \\
\hline Joint involvement & 27 & 43 \\
Abdominal pain & 14 & 22 \\
Abdominal pain and intestinal bleeding & 11 & 17.5 \\
Joint involvement and intestinal bleeding & 9 & 14 \\
Renal involvement & 2 & 3 \\
\hline
\end{tabular}


abdominal involvement $(p=0.006)$ and renal involvement $(p=0.000)$.

Hospitalization: A total of 63 patients (19\%) required hospitalization. The reasons for it are described in Table 4.

Non-steroidal anti-inflammatory drugs (NSAIDs) were required in 56 patients $(16.5 \%)$ and corticosteroids, in $16 \%$. NSAIDs were mostly administered for joint involvement; corticosteroids, for severe abdominal involvement, joint and abdominal involvement or severe renal disorders; whereas antibiotics were given for Streptococcus or Mycoplasma infection.

Persistent purpura: Four patients had persistent purpura during at least 1 year of follow-up, with intermittent abdominal and renal symptoms; two of them had a positive throat swab for Streptococcus on several occasions.

\section{Lab tests}

Leukocytosis (>15 000) was observed in 45 patients $(13 \%)$; platelets $>450000 \mathrm{~mm}^{3}$, in 57 patients $(16.8 \%)$. The median CRP was 0.8 $\mathrm{mg} / \mathrm{dL}(\mathrm{r}=0-18)$; and the median erythrocyte sedimentation rate, $15.5 \mathrm{~mm} /$ hour $(\mathrm{r}=2-88)$. $\operatorname{Ig} \mathrm{A}$ levels were determined in 89 patients $(26 \%)$; in $95 \%$ of cases, IgA was high for age. C3 and C4 values were obtained in 153 patients (45\%); in all cases, the result was normal. In the end, 111 patients $(33 \%)$ withdrew from the follow-up.

\section{DISCUSSION}

For this review of a ten-year experience at the moderate risk office of a public hospital, 339 patients diagnosed with HSP (as per the Ankara criteria) were registered. Patients' age at onset was similar to that reported by different authors. It has been confirmed that, although HSP may occur at any age, it is more common among school-age children. No differences were noted in terms of sex. This is different from other series that have reported a higher prevalence among males. ${ }^{3,18}$

Seasonal distribution was observed to be similar. ${ }^{2-4,19}$ In those studies, HSP usually occurs in the fall and winter. More than $80 \%$ of patients had upper airway conditions. Although the cause of seasonal distribution is unknown, it is probably related to the action of triggering factors, such as infectious agents.

In all cases, the presence of purpura (diagnostic criterion) was confirmed. Although it is typically present since the onset, "atypical" forms of HSP have been described with other signs and symptoms that develop prior to skin lesions. These forms have been described in $15 \%$ of participants in a series of 430 children aged 2-14 years in Turkey ${ }^{2}$ and in $25 \%$ of participants in another study done in Italy $(\mathrm{n}=150){ }^{3}$ In our study, $22 \%$ of subjects started, in general, with joint involvement.

Besides skin involvement, HSP typically affects several other organs. Joint and abdominal manifestations have been reported as the second and third most common clinical manifestations, but their prevalence varies depending on the publication. Abdominal pain has been assessed in different studies and ranges from 35 to $50 \%$ of patients; whereas joint involvement varies from 45 to $75 \%$. $^{2,3,17,19}$ Abdominal involvement was recorded in half of children seen due to this condition in the 10-year study period. Abdominal pain was the main symptom, followed, to a lesser extent, by gastrointestinal bleeding. Intussusception has been reported as an uncommon complication (1\%), which has been consistent with our findings (2 patients). Although gastrointestinal bleeding in these cases was severe, their clinical course was favorable.

In our study, the incidence of joint involvement was higher than what has been described in the bibliography. This information may have been overestimated due to the retrospective nature of data collection from medical records. Consistent with other publications, joint involvement more commonly affects the lower limbs.

The clinical course of patients with HSP is mostly favorable. Morbidity in the acute stage and the need for hospitalization are mainly related to abdominal and/or joint involvement. Long-term morbidity is related to the extent of renal involvement. ${ }^{20}$ According to different studies, its incidence ranges from 10 to $60 \%$.,3,17,19

In this study, renal alterations were observed in $19 \%$ of patients, and in more than $80 \%$ of these, manifestations started within 2 months after onset. This is consistent with other reports,, 119 but the frequency has been lower than that reported by other authors. ${ }^{2,3,17,19}$ The median follow-up duration in our study was 75 days, but almost $30 \%$ of patients withdrew from followup; therefore, renal alterations, which may occur in the long term, may have been underestimated. Consistent with other studies, hematuria was the most common finding. ${ }^{2,3,19}$ Among patients with renal involvement, $22 \%$ had moderate to severe nephritis. The series described here used the modified protocol proposed by Niaudet, based 
on clinical criteria. There is still controversy in relation to the management of these patients.

Different factors have been related to a higher risk for renal involvement: ${ }^{21}$ age older than 10 years, presence of abdominal involvement, persistent purpura, and laboratory alterations (leukocytosis, increased platelet count, antistreptolysin O [ASO], reduced C3 and C4). The series described here found an association with age ( $>10$ years old), abdominal involvement, and recurrence.

The latter have been mentioned in several publications, with a frequency that ranges from $7 \%$ in Turkey, $15 \%$ in Spain, $33 \%$ in the USA, to $35 \%$ in Italy. $3,18,19,22$ In our series, recurrences were detected in $15 \%$ of cases, with a median of 65 days until onset.

Lab tests are not used to diagnose HSP. Our data shows a leukocytosis rate of $13.3 \%$, lower to what has been reported. ${ }^{2,3}$ The literature includes mentions to high IgA levels between 20 and $50 \% .{ }^{23}$ Although routine IgA levels were not tested in the patients of this study, among those who had IgA results, 95\% showed high levels.

A weakness of this study was the lack of long-term evolutionary data. On the one side, follow-up duration may have been affected by the dropout rate (approximately $30 \%$ of patients) and, on the other, by the subsequent changes in the follow-up protocol. In recent years, follow-up duration has extended due to the importance of continued monitoring of renal involvement after the acute stage.

The prognosis of patients with HSP is generally very good; in the absence of significant renal involvement, most patients recover in the first month after onset. Most patients with renal involvement develop it in the first 2 months $\left(90 \%\right.$ ), and $97 \%$, within 6 months. ${ }^{20}$ However, follow-up should continue for a year after initial onset. In the first 2 months, the recommendation is to control patients' blood pressure and urine analysis results every week, and then to space controls to once a month or every 2 months. Considering the potential for late manifestations, urine analysis and blood pressure should be monitored yearly as part of the routine pediatric assessment in children with a history of HSP.

Renal function should be monitored in children with abnormal urine tests; those with persistent proteinuria, HTN or renal failure should be assessed by a pediatric nephrologist. Pregnant women with a history of HSP should be monitored due to their higher risk for HTN. ${ }^{24}$

\section{REFERENCES}

1. López Saldaña D. Púrpura de Schönlein-Henoch. Protoc Diagn Ter Pediatr. 2002; 4:81-4.

2. Anil M, Aksu N, Kara OD, Bal A, et al. Henoch-Schönlein purpura in children from western Turkey: a retrospective analysis of 430 cases. Turk J Pediatr. 2009; 51(5):429-36.

3. Trapani S, Micheli A, Grisolia F, Resti M, et al. Henoch Shönlein Purpura in Childhood: Epidemiological and Clinical Analysis of 150 cases over a 5-year period and review of literature. Semin Arthritis Rheum. 2005; 35(3):143-53.

4. Yildiz C, Ozen S. Childhood Vasculitis. Acta Med. 2013; 2:16-22.

5. Eleftheriou D, Brogan PA. Vasculitis in children. Best Pract Res Clin Rheumatol. 2009; 23(3):309-23.

6. Trnka P. Henoch-Schönlein purpura in children. J Paediatr Child Health. 2013; 49(12):995-1003.

7. Iannetti L, Zito R, Bruschi S, Papetti L, et al. Recent Understanding on Diagnosis and Management of Central Nervous System Vasculitis in Children. Clin Dev Immunol. 2012; 2012:698327.

8. Chen SY, Chang KC, Yu MC, Asueh S, et al. Pulmonary Hemorrhage Associated with Henoch-Schönlein Purpura in Pediatric Patients: Case Report and Review of the Literature. Semin Arthritis Rheum. 2011; 41(2):305-12.

9. Kaur S, Maheshwari A, Aneja S, Seth A, et al. HenochSchönlein purpura with uveitis: an unusual case and review of literature. Rheumatol Int. 2012; 32(12):4057-9.

10. Migita M, Hayakawa J, Shima H, Kobayashi H, et al. A Case of Henoch-Schönlein Purpura with rare complications: necrosis of the small intestine, neurological symptoms, and pericardial tamponade. J Nippon Med Sch. 2005; 72(6):383-6.

11. McCarthy H, Tizard E. Diagnosis and management of Henoch-Scönlein purpura. Eur J Pediatr. 2010; 169(6):643-50.

12. Campos SR. Púrpura de Schönlein-Henoch. ProtocDiagn Ter Pediatr. 2014; 1:131-40.

13. [Smith G. Management of Henoch-Schönlein purpura. J Pediatr Child Health. 2012; 22(8):327-31.

14. Jauhola O, Ronkainen J, Koskimies O, Ala-Houhala M, et al. Clinical course of extrarenal symptoms in HenochShönlein purpura: a 6-month prospective study. Arch Dis Child. 2010; 95(11):871-6.

15. Rahman R, Cobeñas C. Púrpura de Schönlein-Henoch. In Comité Nacional de Nefrología Pediátrica. Nefrología Pediátrica. Buenos Aires: FUNDASAP; 2008.Pages 226-30.

16. Alfredo CS, Nunes NA, Len CA, BArbosa CM, et al. HenochSchönlein purpura: recurrence and chronicity. J Pediatr (Rio J). 2007; 83(2):177-80.

17. Praism D, Amir J, Nussinovitch M. Recurrent HenochSchönlein purpura in children. J Clin Rheumatol. 2007; 13(1):25-8.

18. Niaudet $P$, Habib R. Methylprednisolone pulse therapy in the treatment of severe forms of Schönlein-Henoch purpura nephritis. Pediatr Nephrol. 1998; 12(3):238-43.

19. Saulsbury F. Henoch-Schonlein purpura in children. Report of 100 patients an review of the literature. Medicine (Baltimore). 1999; 78(6):395-409.

20. Narchi H. Risk of long term renal impairment and duration of follow up recommended for Henoch-Schönlein purpura with normal or minimal urinary findings: a systematic review. Arch Dis Child. 2005; 90(9):916-20.

21. Chan H, Tang YL, Lv XH, Zhang GF, et al. Risk Factors associated with Renal Involvement in Childhood Henoch-Schonlein Purpura: a Meta-Análisis. Plos One. 2016; 11(11):e0167346.

22. Ángeles L, Ballona R. Púrpura de Henöch-Schönlein: epidemiología, clínica y seguimiento por cinco años en pacientes hospitalizados en el Instituto Especializado de Salud del niño, 1995-1999. Folia Dermatol. 2007; 18(3):111-7. 
23. Piram M, Mahr A. Epidemiology of immunoglobulin A vasculitis (Henoch-Schönlein): current state of knowledge. Curr Opin Rheumatol. 2013; 25(2):171-8.
24. Ronkainen J, Nuutinen M, Koskimies O. The adult kidney 24 years after childhood Henoch-Schönlein purpura: a retrospective cohort study. Lancet. 2002; 360(9334):666-70. 